\title{
Contextual Sources of Perceived Group Threat: Negative Immigration-Related News Reports, Immigrant Group Size and their Interaction, Spain 1996-2007
}

\author{
Elmar Schlueter ${ }^{1, *}$ and Eldad Davidov ${ }^{2}$
}

\begin{abstract}
This study attempts to further our understanding of the contextual sources of anti-immigrant sentiments by simultaneously examining the impact of immigrant group size, negative immigration-related news reports and their interaction on natives' perceived group threat. We test our theoretical assumptions using repeated cross-sectional survey data from Spain during the time period 1996-2007, enriched with regional statistics on immigrant group size and information from a longitudinal content analysis of newspaper reports. Drawing on multilevel regression models, our findings show that a greater number of negative immigration-related news reports increases perceived group threat over and above the influence of immigrant group size. Additionally, our findings indicate that the impact of negative immigration-related news reports on perceived group threat is amplified (weakened) in regions with a smaller (larger) immigrant group size. Collectively, these results testify to the importance of immigrant group size and negative immigration-related news reports as key contextual sources of natives' perceived group threat.
\end{abstract}

\section{Introduction}

A major goal of research on ethnic inequalities between immigrants and natives is to further the understanding of the sources underlying natives' anti-immigrant sentiments. To attain this goal, group threat theory has provided fertile ground for investigation (Blumer, 1958; Blalock, 1967; LeVine and Campbell, 1972; see Coenders, 2001; Schlueter, Wagner and Schmidt, 2008; Ceobanu and Escandell, 2010). The majority of studies following a group threat perspective generally investigate the extent to which a larger immigrant group size heightens the perceptions of threatened group interests in members of the native population (Scheepers, Gijsberts and Coenders, 2002; Semyonov, Raijman and Gorodzeisky, 2006). Parallel to this line of research, one long-standing proposition advanced in the group threat literature is that perceived threats and anti-minority sentiments are centrally shaped by negative mass media portrayals of minority groups (Allport, 1954; Blumer, 1958). However, in sharp contrast to the large and growing number of studies focusing on immigrant group size, the role the mass media play in forming anti-immigrant sentiments has thus far received only limited empirical attention. This relative neglect of potential mass media influences is unfortunate, and not only because researchers miss a potentially important factor by which to understand the prevalence of anti-immigrant sentiments. The existing findings pertaining to the impact of immigrant group size on anti-immigrant sentiments may, for example, also be biased to the extent that negative mass media portrayals of immigrants are correlated with immigrant group size. Furthermore, empirical assessments that do not incorporate both immigrant group size and the mass media simultaneously miss the opportunity to discover how these factors interact in shaping the hostile ethnic stances of natives. Collectively, these observations underscore the need to include the mass media in research on the sources of anti-immigrants sentiments. In part, the relative omission of the mass media in previous work is

\footnotetext{
${ }^{1}$ University of Cologne, Institute of Sociology, Greinstr. 2, 50939 Cologne, Germany; ${ }^{2}$ University of Zurich, Institute of Sociology, Andreasstr. 15, CH-8050 Zurich, Switzerland.

${ }^{\star}$ Corresponding author. Email: elmar.schlueter@wiso.uni-koeln.de

(C) The Author 2011. Published by Oxford University Press. All rights reserved.

For permissions, please e-mail: journals.permissions@oup.com. Submitted: May 2010; revised: June 2011; accepted: June 2011.
} 
possibly due to the lack of adequate data sources. However, improved facilities for conducting standardized content analysis of newspaper reports in conjunction with the increasing availability of longitudinal survey data have opened up new horizons for scholarly pursuit. In keeping with a group threat approach, in this research we take advantage of these novel opportunities. We attempt to expand upon earlier work in this field by specifying and testing three hypotheses to what extent (i) immigrant group size, (ii) negative immigrationrelated news reports and (iii) the interaction of these sources explain variation in natives' perceived group threat between regions and over time. We examine our predictions from a conceptual and methodological multilevel perspective, drawing on repeated cross-sectional survey data from 17 regions and 12 years linked with contextual characteristics.

The site of our study is Spain. Whereas this country has only become a destination for large-scale immigration in the last decade, today already one out of ten residents in Spain is a member of the immigrant population. At the same time, immigration has become a key topic in the public debate. Accordingly, Spain represents a national setting that is well-suited to examine the independent and interactive influences of immigrant group size and negative immigration-related news reports on perceived group threat of native Spaniards.

\section{Theoretical Background}

To clarify the phenomenon we are seeking to explain, we define perceived group threat as the natives' anticipation of negative consequences for their own group due to the presence of immigrants (Schlueter and Wagner, 2008; see Stephan and Renfro, 2002). This definition encompasses two key implications. First, as its name suggests, the concept of perceived group threat stresses that tense interethnic relations between natives and immigrants represent group-level processes (Tajfel, 1978). This means that even if natives see their personal interests to be unaffected by immigrants, they still might consider immigrants to threaten their own group's interests (Riek, Mania and Gaertner, 2006: 337). Second, perceptions of threatened group interests might refer to a variety of issues, ranging from the opinion that immigrants reduce the opportunities of natives in the housing or labor markets to beliefs that the cultural habits of immigrants conflict with the symbolic order of the host society. Thus, to explain variation in perceived group threat across regions and over time, it seems particularly adequate to consider characteristics of the contexts in which the intergroup relations between natives and immigrants take place. This study focuses on two such contextual characteristics: immigrant group size and negative immigration-related news reports.

\section{Immigrant Group Size}

The approach most often used in studies following a group threat framework traces anti-immigrant attitudes to the relative size of the immigrant population. At its core, this line of research posits that a larger immigrant group size in a given locality intensifies intergroup strugglewhether real or imaginary-with natives for important political, economic, or cultural group-level resources. The harm that natives expect from such conflicting intergroup interests is reflected by perceived group threat. The relative size of the immigrant population alone, however, may not be sufficient to induce perceptions of group threat among natives. Rather, immigrants need to become visible for threat responses to emerge (Allport, 1954). To illustrate, it seems plausible that greater differences in physical appearance, dress code, and language increase the visibility of immigrants (Hagendoorn and Pepels, 2003; Hjerm, 2009). Given such visibility, both negative direct experiences with immigrants as well as information from fellow in-group members (Allport, 1954: 264) might then influence natives' perceptions that immigrants pose a threat to their in-group.

\section{Negative Immigration-Related News Reports}

A second argument found in the group threat literature is that anti-minority sentiments are strongly shaped by the mass media (Allport, 1954: 200; Blumer, 1958: 5). This line of explanation builds upon the general notion that the mass media represent a central source of information for people's attitudes toward other people, issues or objects. The assumption is that if the number of mass media reports providing negative information on a minority group rises, such negative information will come to majority members' minds most readily and anti-minority sentiments will increase (Persson and Musher-Eizenmann, 2005; Shrum, 2009). In fact, researchers widely agree that the mass media depict immigrants in a predominantly negative tone and as a threat to the host society (ter Wal, 2003; ter Wal, d'Haenens and Koeman, 2005). To investigate the presumed link between news reports and natives' perceived group threat, we conceive of negative news reports of immigrants as a contextual characteristic that primarily varies over time. ${ }^{1}$ Two arguments support this conceptualization. First, news reports on immigrants and immigration are known to show overall relatively little regional variation. Second, conceptualizing negative news reports of immigrants 
as a contextual characteristic accounts for the idea of indirect mass media influences (Boomgaarden and Vliegenthart, 2009). Direct, personal exposure to negative immigration-related news reports might well represent an important channel through which the mass media can shape perceived group threat. However, it has long been established that 'the media's influence can reach and affect even those who do not watch, read or listen' (Zucker, 1978: 226; see also Peter, 2004: 146), for example, via conversations in social networks (SchmittBeck, 2003). Consequentially, direct exposure is not a necessary condition for mass media influences on perceived group threat to occur.

\section{Interactive Relations}

Thus far, we considered the ways immigrant group size and negative immigration-related news reports bear on perceived group threat separately. We now discuss how these contextual sources might interact in shaping perceived group threat. Indeed, developing and testing interactive relations among the sources of ethnic sentiments has long been deemed central to achieve a more comprehensive understanding of interethnic relations (Pettigrew, 1985: 330). How, then, would immigrant group size and negative immigration-related news reports interact in contributing to perceptions of threatened group interests? From previous theory and research, we develop two competing explanations. A first line of explanation contends that the effect of negative immigration-related news reports on perceived group threat increases with a larger immigrant group size. This expectation is based on the rationale that a larger immigrant group size raises the salience of interethnic competition between natives and immigrants. Given such enhanced salience of interethnic competition, then, the information provided by negative immigration-related news reports presumably becomes more relevant for the formation of natives' ethnic sentiments (Boomgaarden and Vliegenthart, 2009; see also Hopkins, 2010). In contrast to this perspective, a second line of explanation contends that the effect from negative immigration-related news reports on perceived group threat increases with a smaller immigrant group size. This view derives from the basic notion that the less direct experience the people have with a given issue area, the more they will rely on the news media for information and interpretation in that area' (Zucker, 1978: 227; see also Zaller, 1996: 17, Newton, 2006: 18). Thus, when opportunities for negative direct experiences with immigrants as indicated by a smaller immigrant group size are small, it is negative immigration-related news reports which become the informational basis for perceived group threat.

\section{Hypotheses}

We specify four hypotheses to examine the empirical adequacy of our theoretical assumptions. Our general expectation regarding the role that immigrant group size plays for natives' perceptions of group threat is formulated as follows:

Hypothesis 1: The larger the relative size of the immigrant population, the more perceived group threat

Turning to the negative immigration-related news reports as a factor shaping perceived group threat, we expect that:

Hypothesis 2: The more negative immigration-related news reports, the more perceived group threat

We furthermore discussed two alternative ways how immigrant group size and negative immigration-related news reports might interact in shaping perceptions of threatened group interests. Based on these considerations, we put forth two competing hypotheses:

Hypothesis 3a: The effect of negative immigration-related news reports on perceived group threat increases with a larger immigrant group size.

Hypothesis 3b: The effect of negative immigration-related news reports on perceived group threat increases with a smaller immigrant group size.

\section{Research Setting}

Before turning to the empirical analyses, we briefly describe the setting of our study-Spain. Unlike established European immigration countries like France, the Netherlands, or Germany, Spain only started to become a destination for immigrants in the second half of the 1980s. Around that time, a rising economic prosperity coupled with growing labour shortages induced initial immigrant inflows to Spain (Arango, 2000). Ever since, annual immigration rates have been rising at an unprecedented pace. For example, from 1996 to 2007, the proportion of the immigrant population in Spain increased from 1.2 to 11.4 per cent (INE, 2008). Likewise, immigrant origins have diversified, with the largest shares of immigrants coming from African, Asian, Eastern European, and Latin American countries (Corkill, 2001). ${ }^{2}$ Parallel to this massive change in the ethnic composition of the Spanish society, since the mid-1990s, issues related to immigrants and immigration 
have recurrently figured high on the country's political and public agenda. The topics dealt with in the national mass media reflect this development-and provide no exception to the robust finding that, in the mass media, issues related to immigration and immigrants are generally problematized. In fact, the largest share of Spanish newspaper reports focusing on matters of immigration and immigrants accentuate the negative aspects thereof (Agrela, 2002; van Dijk, 2006). Given these conditions, Spain clearly represents an instructive test case for examining our hypotheses. It is this task to which we turn next.

\section{Data and Measures}

Testing our hypotheses required the combination of multiple data sources. To address this need, we constructed a single dataset integrating (i) individual data from 12 repeated cross-sectional surveys and (ii) official statistics concerning the annual proportion of immigrants across 17 regions and (iii) information from a quantitative content analysis of newspaper articles dealing with immigration-related issues.

(i) To operationalize our individual level constructs, we take advantage of the 'Attitudes towards Immigrants Surveys' (ASEP/JDS, 2008). Data from this cross-sectional survey series were collected by means of face-to-face interviews utilizing nationally representative stratified random samples of the Spanish general population aged 18 years and older. One particularly desirable feature of these data is the opportunity to assess variation in individual perceptions of group threat between regions and over time, a necessary feature for examining our theoretical propositions outlined above. Specifically, we draw on data spanning the 12 annual surveys collected between 1996 and 2007. Selecting this time period is essential because prior to 1996 neither significant numbers of immigrants arrived in Spain nor did the Spanish mass media devote much attention to issues related to immigration and immigrants. ${ }^{3}$ Identifying the appropriate local level of analysis was a more difficult task. Whereas the surveys contained information on both the provinces (smaller local units) and regions (larger local units) respondents were living in during data collection, group threat theory itself offers little guidance concerning the adequate spatial contexts for testing its predictions. To find out at which local level differences in perceived group threat were most pronounced, we compared the sizes of the intraclass correlations in perceived group threat for both provinces and regions. The results indicated that perceptions of threatened group interests differed rarely between provinces, but to a substantial degree between regions. Accordingly, the final sample comprised a total of 14,511 individuals simultaneously nested in 17 regions and 12 annual surveys (further information about the sample may be obtained from the first author upon request).

\section{Dependent Variables}

We used three items to form an index measuring perceived group threat. While each item taps a different substantial domain, all items reflect the view that immigrants endanger the well-being of the host society-our general definition of perceived group threat. Specifically, the first item asks 'In general terms, what would you say about the number of people of a different nationality, race, religion or culture who live in our country?' Response options were comprised of three categories: $1=$ not too many, $2=$ many and $3=$ too many. Consistent with previous research, we take a negative evaluation of the number of immigrants living in the host society to indicate a sense of perceived threat. The second item gauges respondents' evaluation of the statement 'Foreign immigration will cause Spain to lose its identity.' This indicator clearly refers to a contested cultural issue. Response options were given on a five-point scale ranging from 1 (strongly disagree) to 5 (strongly agree). The third item refers to a rather direct threat to the well-being of the in-group by asking 'Do you think that immigrants from less developed countries who live in Spain have contributed to an increase of delinquency in Spain or, on the contrary, that they haven't had a significant effect on this matter?' The dichotomous answer option for this item was coded as $1=$ no effect and $2=$ more crime. Internal consistency of the three items proved to be sufficient (Cronbach's $\alpha=0.67$ for the total sample; $0.55-0.67$ for the annual samples). ${ }^{4} \mathrm{We}$ then averaged the three items to produce a single measure of perceived group threat.

\section{Independent Variables}

Immigrant group size. We operationalize immigrant group size as the percentage of non-Western immigrants relative to the regional total population. Non-Western immigrants are defined here as all those immigrants without Spanish citizenship, who originated from African, Asian, Eastern European, or Latin American countries. Coding the size of the immigrant population in this way maintains comparability with prior research also conceptualizing non-Western immigrants as an objective source of subjective threat perceptions (Scheepers et al., 2002; Semyonov et al., 2006). All data were drawn from the National Statistics Institute (INE, 2008). ${ }^{5}$ 
Negative immigration-related news reports. To gauge the intensity of negative mass media coverage of immigration-related issues, we conducted a quantitative content analysis of digitally available newspaper articles. Specifically, our content analysis draws on the digital full texts for the national quality broadsheet 'El Pais' provided by LexisNexis (2008). Two reasons support selecting this news outlet. First, 'El Pais' is the national newspaper with the highest circulation number and, therefore, is most likely to reach a broad audience. Second, due to its status as one of the leading Spanish newspapers, 'El Pais' provides an adequate proxy for assessing the mass media coverage of immigrationrelated issues in Spain. The goal of this content analysis was to obtain frequency scores of newspaper articles reporting on negative issues relating to immigrants and immigration in Spain for the period under study. To this end, we first developed a dictionary of keywords indicating negative issues related to immigrants and immigration based on findings from existing contentanalytical studies (CIPIE, 1999; van Dijk, 2006). These keywords then served to construct a Boolean search string to select all corresponding newspaper articles. ${ }^{6}$ To illustrate, we identified newspaper articles reporting on topics such as acts of delinquency or crime associated with immigrants, illegal immigration, conflicting cultural differences or labor market competition between immigrants and natives, and immigration laws or problems associated with the integration of immigrants as more generally reflecting negative issues relating to immigrants and immigration. The next task was to determine an appropriate time span from which to select relevant news articles. Taking into account that mass media influences on public opinion have been found to unfold over the periods of a few days to several weeks (Dearing and Rogers, 1996), we opted to content-analyze all articles published up to 8 weeks prior to the field phases of the annual surveys. ${ }^{7}$ Subsequently, we conducted a manual reanalysis to check for possible problems with the issue content of the automatically selected articles (Schafraad, Wester and Scheepers, 2006; Neuendorf, 2007). ${ }^{8}$ Summarizing the absolute numbers of articles for each of the 8-week period preceding the 12 annual surveys yielded the frequency scores we use to assess the intensity of negative news coverage on immigration-related issues.

\section{Control Variables}

To hold differences in the population composition between regions and over time constant, we include several individual variables in our models, such as gender, age, unemployment status and educational attainment. ${ }^{9}$ The reference category of the dichotomous variable for gender is male $(1=$ female $)$. To control for the influence of respondents' age, the number of years is coded in four categories: $1=18-29$ years (reference category), $2=30-49$ years, $3=50-64$ years, $4=\geq 65$ years. Respondents' unemployment status is operationalized using a dummy variable ( $1=$ unemployed). Educational attainment is assessed with a variable coded in nine categories ranging from 0 (respondent cannot read), 1 (respondent can read), 2 (primary education), 3 (general basic education), 4 (vocational training), 5 (secondary school certificate), 6 (university orientation), 7 (college) to 8 (respondent has a university degree). Finally, although the extant literature reveals no clear pattern of results on whether local deteriorating economic conditions relate to anti-immigrant sentiments or not, we also control for the regional unemployment rate in our models. Regional percentages of unemployed persons are drawn from the National Statistics Institute (INE, 2008). Interested readers may find additional descriptive statistics in the appendix in the supplementary data.

\section{Method}

Individuals (level 1) in our data are nested in regions (level 2) which are nested in years (level 3). To adequately deal with this three-level data structure, we employ hierarchical multilevel regression models. This technique offers a flexible and powerful analytical approach to overcome the statistical complexities typically associated with nested data structures, such as deflated standard errors (Hox, 2002; Luke, 2004). We estimated all models using maximum likelihood techniques. ${ }^{10}$ In order to gauge the relative amount of variance situated at the three different levels of analysis, we first specified a random effects ANOVA model:

$$
Y_{i j k}=\gamma_{000}+u_{00 k}+r_{0 j k}+\varepsilon_{i j k}
$$

Here, $Y_{i j k}$ is the score in perceived group threat for an individual $i$ nested in region $j$ and year $k$. Equation (1) shows that this score is a function of the grand mean $\gamma_{000}$ and three random parameters. The first random parameter, $u_{00 k}$, represents the random year effect. This is the extent to which the average threat score at year $k$ differs from the grand mean due to specific attributes of the $k$-th year. The second random parameter, $r_{0 j k}$, represents the random region effect. This equals the extent to which the average threat score in the $j$-th region differs from the grand mean due to characteristics associated with region $j$. The third random effect, $\varepsilon_{i j k}$, denotes the deviation of individual $i$ nested in region $j$ and year $k$ from the grand mean because of characteristics specific for individual $i$. The results from this 
model allow the calculation of two intraclass correlation coefficients (ICC) indicating the variance situated at the regional level and the year level (Hox, 2002). The results indicate that 8.8 percent $[=0.031 /(0.031+0.031+$ $0.291) \times 100$ ] of the total variance in perceived group threat is due to differences between regions. The relative amount of variance in perceived group threat due to differences over time is (coincidentally) also estimated to equal $\sim 8.8$ per cent. These preliminary findings indicate fairly substantial amounts of contextual variance and thus call for further investigation. Accordingly, at level 1 our final model is:

$$
\begin{aligned}
Y_{i j k}= & \pi_{0 j k}+\pi_{1}(\text { sex })_{i j k}+\pi_{2}(\text { age })_{i j k} \\
& \left.+\pi_{3} \text { (unemployed }\right)_{i j k}+\pi_{4}(\text { education })_{i j k}+\varepsilon_{i j k}
\end{aligned}
$$

As before, $Y_{i j k}$ represents the score in perceived group threat for individual $i$ in the $j$-th region at the $k$-th year. Equation (2) specifies the level 1 intercept $\pi_{0 j k}$ to vary across both $j$ regions and $k$ years. The slopes associated with the covariates gender, age, being unemployed, and educational attainment all account for individual differences in perceived group threat within region $j$ nested in year $k$ and are treated as fixed. ${ }^{11}$ Because the model includes predictor variables, $\varepsilon_{i j k}$ now represents the residual random effect of individual $i$ in the $j$-th region at the $k$-th year. At level 2, the variation in the level 1 intercept $\pi_{0 j k}$ is modelled to be influenced by the regional percentage of non-Western immigrants and the regional unemployment rate:

$$
\begin{aligned}
\pi_{0 j k}= & \beta_{00 k}+\beta_{01}(\text { immigrant group size })_{j k} \\
& +\beta_{02}(\text { unemployment rate })_{j k}+r_{0 j k}
\end{aligned}
$$

Equation (3) shows that $\pi_{0 j k}$ is a function of $\beta_{00 k^{-}}$ which is the average score in perceived group threat across regions $j$ - and the slope $\beta_{01}$ associated with immigrant group size. The influence of the regional unemployment rate is indicated by $\beta_{02}$. The residual random effect for $\beta_{00 k}$ is labeled as $r_{0 j k}$. Moving to level 3, equation (4) indicates that the level 2 intercept $\beta_{00 k}$ is decomposed into the grand mean $\gamma_{000}$, the slope $\gamma_{001}$ associated with the number of negative immigrationrelated news reports plus the slope $\gamma_{002}$ associated with the interaction between negative immigration-related news reports and immigrant group size.

$$
\begin{aligned}
\beta_{00 k}= & \left.\gamma_{000}+\gamma_{001} \text { (negative news reports) }\right)_{k} \\
& +\gamma_{002} \text { (negative news reports } \\
& \times \text { immigrant group size })_{k}+u_{00 k}
\end{aligned}
$$

Given the relatively low number of time-level units, we treat the slope of immigrant group size as fixed when testing for the theoretically expected cross-level interaction between immigrant group size and the number of negative news reports (Snijders and Bosker, 1999; LaHuis and Ferguson, 2009). Finally, the residual random effect corresponding to $\beta_{00 k}$ is represented by $u_{00 k}$.

\section{Results}

There are two parts to this section. We first explore the bivariate associations among our key variables. These descriptive findings provide the backdrop for the results from the hypotheses testing based on multilevel regression modelling.

\section{Bivariate Associations}

Figure 1 depicts the regional-level association between immigrant group size and aggregate scores of perceived group threat $\left(N_{\mathrm{jk}}=204\right.$ region-year combinations, i.e., 17 regions $\times 12$ years). ${ }^{12}$ The figure clearly shows that a larger regional proportion of immigrants is associated with higher perceived group threat.

Figure 2 shows the association between the annual frequency of negative immigration-related news reports and aggregate scores of perceived group threat over time ( $N_{\mathrm{k}}=12$ years). We first note a pronounced increase in the frequency of negative immigration-related news reports over time. For example, for the period from 1996 to 2001, the number of newspaper articles reporting on negative issues related to immigrants and immigration went up by a factor of 10 . This upward trend continued until it reached its climax in 2006, and declined markedly in the year thereafter. ${ }^{13}$ The figure also demonstrates that perceptions of group threat continuously increased from 1997 until 2006, yet decreased in 2007. The trends in negative immigration-related news reports and perceived group threat thus appear indeed quite similar.

In sum, there is suggestive visual evidence that both immigrant group size and negative immigration-related news reports shape natives' perceived group threat. However, these preliminary findings are based on aggregated data only and do not account for the potential influence of the individual and contextual level control variables. To obtain more conclusive insights, we next turn to the results from the multivariate analysis. Table 1 reports the results from four multilevel hierarchical regression models which build up incrementally. ${ }^{14}$

To facilitate interpretation of the unstandardized regression coefficients, we rescored all non-categorical independent variables to range from a minimum of 0 to a maximum of 1 . A one unit change in these variables thus indicates a movement from the lowest possible score to the highest possible score. We also centered immigrant group size and negative immigration-related news reports around their means to simplify the interpretation 


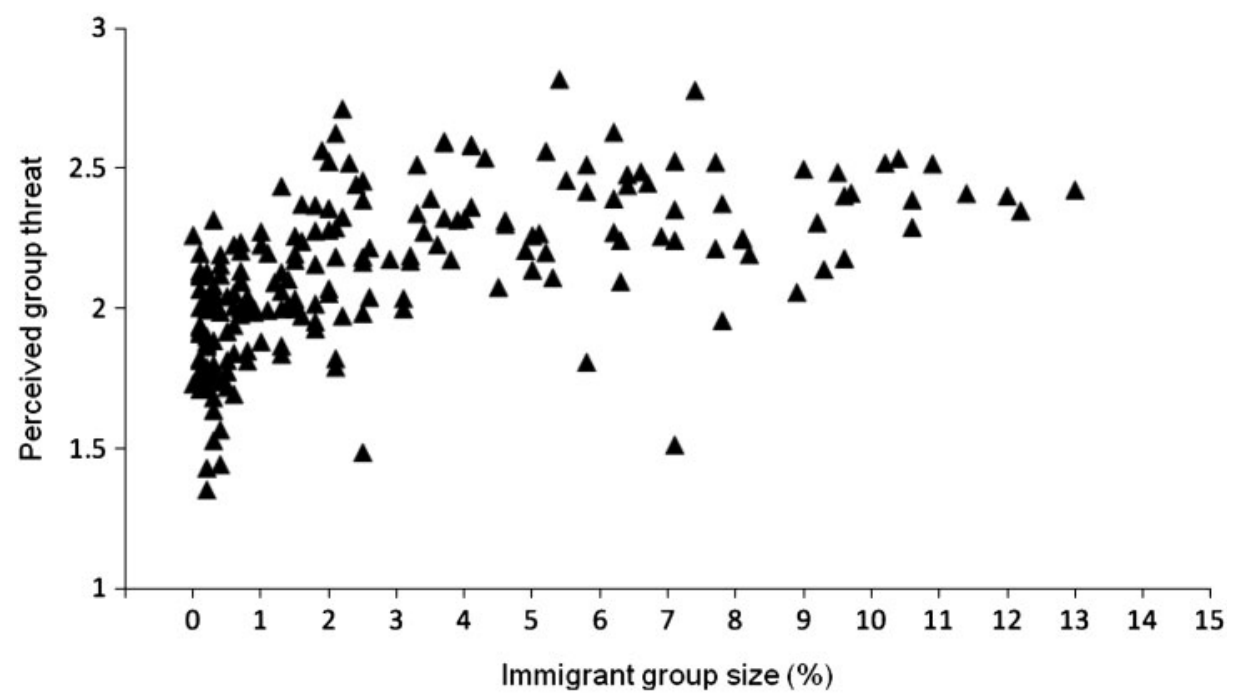

Figure 1 Perceived group threat and immigrant group size. Note: Triangles indicate $N_{\mathrm{j}}=204$ region-year combinations

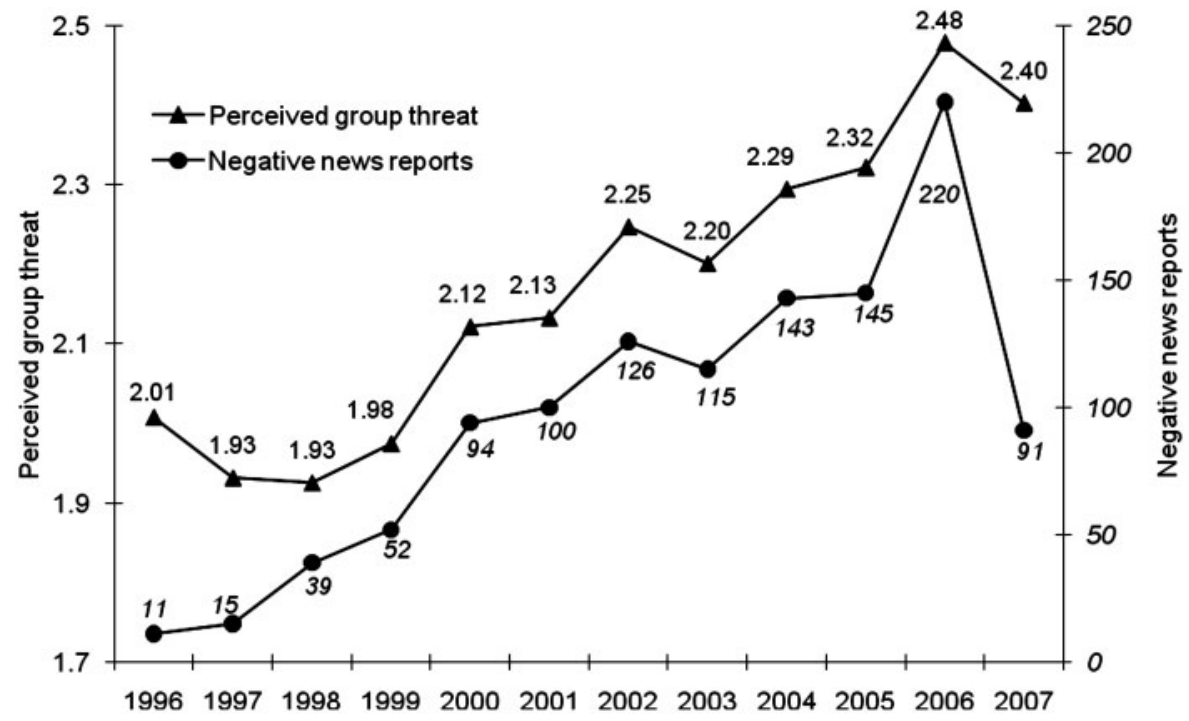

Figure 2 Perceived group threat and negative immigration-related news reports $\left(N_{k}=12\right.$ years)

of the slope of the interaction between these variables. The results are presented in Table 1. Model (1) expands upon the previously described random effects ANOVA by regressing perceived group threat on the individual and contextual level control variables. The results reconfirm existing knowledge by showing that higher educational attainment is associated with reduced perceived group threat $(b=-0.39, P<0.001)$. Of primary interest is the finding that the magnitude of the between-region and over-time variance components remains substantial when accounting for these characteristics. This indicates that compositional differences are only of minor relevance for explaining differences in perceptions of threatened group interests between regions and over time. Likewise, the data reveal no significant influence from the regional unemployment rate on perceptions of threatened group interests among natives. ${ }^{15}$ Model (2) investigates our first hypothesis. As theoretically expected, we find that the influence of immigrant group size on perceived group threat is significantly positive $(b=0.34$, 
Table 1 Multilevel hierarchical regression analysis of perceived group threat (standard errors in parentheses)

\section{Variables}

Model (1)

$\begin{array}{ll}2.29^{* *} & (0.053) \\ -0.001 & (0.008) \\ & \\ -0.005 & (0.011) \\ 0.076^{* *} & (0.013) \\ 0.064^{* *} & (0.014) \\ -0.019 & (0.017) \\ -0.391^{* *} & (0.019) \\ -0.14 & (0.081) \\ - & \\ - & \\ - & \\ & \\ 0.027^{\star *} & (0.012) \\ 0.028^{* *} & (0.003) \\ 0.276^{* *} & (0.003) \\ 22767.292 \\ 22789.292\end{array}$

Model (2)

$\begin{array}{cc}2.3^{* \star} & (0.041) \\ -0.001 & (0.008) \\ & \\ -0.005 & (0.011) \\ 0.076^{\star *} & (0.013) \\ 0.064^{* \star} & (0.014) \\ -0.019 & (0.017) \\ -0.391^{\star *} & (0.019) \\ -0.045 & (0.089) \\ 0.34^{* \star} & (0.082) \\ - & \\ - & \\ & \\ 0.014^{\star} & (0.007) \\ 0.026^{* \star} & (0.003) \\ 0.276^{* \star} & (0.003) \\ 22752.163 \\ 22776.163\end{array}$

Model (3)

$\begin{array}{rrrr}2.3^{\star *} & (0.027) & 2.33^{\star *} & (0.029) \\ -0.001 & (0.008) & -0.001 & (0.008)\end{array}$

Female

Age

$$
\text { 30-49 }
$$

65-max.

Unemployed

Educational attainment

Unemployment rate

Immigrant group size

Negative news reports

Negative news reports $x$

Immigrant group size

$\sigma_{\text {uTime }}^{2}$

$\sigma_{r \text { Regions }}^{2}$

$\sigma_{\varepsilon}^{2}$ Individuals

$-2 \log$ likelihood

AIC
$50-64$

\begin{tabular}{|c|c|c|c|}
\hline-0.005 & (0.011) & -0.005 & $(0.011)$ \\
\hline $0.076^{* *}$ & $(0.013)$ & $0.076^{* *}$ & $(0.013)$ \\
\hline $0.064^{\star \star}$ & $(0.014)$ & $0.064^{\star *}$ & $(0.014)$ \\
\hline-0.019 & $(0.017)$ & -0.019 & $(0.017)$ \\
\hline$-0.391^{\star *}$ & $(0.019)$ & $-0.391^{\star *}$ & $(0.019)$ \\
\hline 0.003 & $(0.088)$ & 0.058 & $(0.08$ \\
\hline $0.331^{\star *}$ & (0.977) & $0.461^{\star *}$ & $(0.089$ \\
\hline $0.427^{\star *}$ & $(0.083)$ & $0.381^{* *}$ & $(0.082)$ \\
\hline- & & $-0.692^{\star}$ & $(0.26$ \\
\hline 0.002 & $(0.002)$ & 0.002 & $(0.002)$ \\
\hline $0.026^{* *}$ & $(0.003)$ & $0.025^{\star *}$ & $(0.003$ \\
\hline $0.276^{* *}$ & $(0.003)$ & $0.276^{* *}$ & $(0.00$ \\
\hline 22735.2 & 47 & 22728.31 & 16 \\
\hline 22761.2 & & 22756.31 & \\
\hline
\end{tabular}

${ }^{* *} P<0.001 ;{ }^{*} P<0.05$.

$P<0.001)$, an effect which also manifests itself as a substantial improvement of model fit $(\Delta-2 \mathrm{LL}=15.13)$. Substantively, this influence means that in regions with a relatively higher proportion of immigrants, natives tend to display heightened perceptions of threatened group interests. ${ }^{16}$ We furthermore observe that even when accounting for the massive inflow of immigrants by including immigrant group size into the model, approximately half of the variation in perceived group threat at the time level remains. Model (3) examines our second hypothesis, according to which an increase in negative immigration-related news reports over time exerts a positive influence on perceived group threat. In support of this assumption, the slope coefficient pertaining to negative immigration-related news reports is significantly positive $(b=0.43, P<0.001) .{ }^{17} \mathrm{~A}$ further drop in the model deviance $(\Delta-2 \mathrm{LL}=16.2)$ lends additional evidence to the relevance of negative immigration-related news reports for shaping perceptions of group threat. Model (4) reports the results for the presumed interactive influences from immigration-related news reports and immigrant group size on perceived group threat. The data reveal a statistically significant interaction term with a negative sign $(b=-0.69, P<0.05)$, a result which is accompanied by a further decrease in the model deviance $(\Delta-2 \mathrm{LL}=6.95)$. Figure 3 visualizes the nature of this interaction. The plot shows that overall, perceived group threat is higher in regions with a larger immigrant group size. However, the effect of negative immigration-related

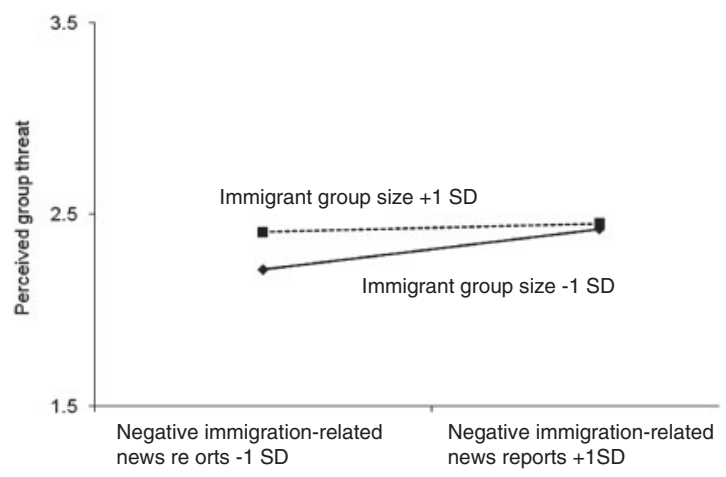

Figure 3 Interaction between negative immigration-related news reports and immigrant group size. Note: Scores are based on 1 standard deviation below or above the variable's mean

news reports on perceived group threat clearly is stronger in regions with a smaller immigrant group size. These findings thus lend empirical support to hypothesis $3 \mathrm{~b}$.

\section{Discussion} immigrant attitudes have largely abstained from investigating the role that the mass media play in explaining such negative ethnic sentiments. This study aimed to
Prior studies on the contextual sources of anti- 
improve this state of research. Guided by a group threat framework, we investigated how negative immigrationrelated news reports shape natives' perceptions of threatened group interests both independently and in interaction with immigrant group size. We examined our predictions from a conceptual and statistical multilevel perspective, drawing upon repeated cross-sectional survey data from Spain for the 1996-2007 period enriched with regional statistics on immigrant group size and information from a longitudinal content analysis of news reports.

The findings from our investigation enhance the existing literature in this field in three significant ways. First, the current study provides evidence that a greater number of negative immigration-related news reports increases perceptions of threatened group interests among natives over time. We take this finding to be of key importance, particularly because it underscores the value of studying mass media influences for improving our knowledge on how contextual sources shape antiimmigrant attitudes. Second, this research also expands upon earlier findings concerning the influence of immigrant group size on perceived group threat. In covering 17 Spanish regions during the time period 1996-2007, this study demonstrates a positive influence of immigrant group size on perceptions of group threat. Interestingly, this finding differs from Escandell and Ceobanu (2009). Focusing on a different dependent variable and the time period 1991-2001, these authors conclude that Spanish citizens' anti-immigrant prejudice is unaffected by the regional immigrant group size. Measurement issues concerning the dependent variables aside, we speculate that one apparent reason to explain these divergent findings is the demographic size of the immigrant population itself. It seems plausible to assume that before the second half of the 1990s, the proportion of immigrants simply remained too small to activate Spanish natives' beliefs of threatened group interest, a situation which-as our study shows - changed drastically in the subsequent years. Finally, this study sheds new light on how news reports and immigrant group size interact in shaping anti-immigrant attitudes. The results indicate that a greater number of negative immigrationrelated news reports exert stronger effects on perceived group threat in regions with a smaller proportion of immigrants. This interactive relation underscores the gains to be achieved from examining the contextual sources of natives' anti-immigrant attitudes between regions and over time simultaneously.

We would like to note the following limitations in this study, in part because they provide useful avenues for additional research. First, in following previous research, we refrained from examining regional variations in negative immigration-related news reports and focused on a single national newspaper source instead. Subsequent studies may productively explore variation in negative immigration-related news reports between different localities. A second issue refers to the rather extensive spatial scale of the regional level units we employed in our analyses. We encourage future research to re-examine our conclusions in alternative settings, for instance, at the city or neighbourhood level. Doing so could offer important insights as to what extent our findings generalize to more proximate contexts of everyday relations between natives and immigrants. A third issue is that this study centrally draws upon repeated cross-sectional survey data. This means that our results are mute with respect to the amount of intraindividual changes in perceived group threat over time, an issue which might be investigated by multiwave panel data. Likewise, our research design cannot establish causal conclusions. On the one hand, we sought to alleviate concerns over the direction of causality by using lagged prediction of negative immigration-related news reports on perceived group threat, and our findings are indeed broadly consistent with related work on mass media influences. On the other hand, it should be acknowledged that widespread negative attitudes toward immigrants might also impact the number of immigration-related negative news reports. Examining these relations more closely remains an important task for future inquiry.

Extensions of the present work might also explore how further individual-level characteristics such as different forms of national identification (Sniderman, Hagendoorn and Prior, 2004; Ullrich, Christ and Schlüter, 2006; Kunovich, 2009) relate to the current pattern of results, and whether these results pertain also when specific minority groups such as Muslims are considered (Strabac and Listhaug, 2008). This study was also partially limited by the lack of available data on how locally occurring negative incidences (e.g. 'disproportionate' problem behaviours among ethnic group members, violent ethnic riots) relate to anti-immigrant attitudes. One implicit assumption made in this study is that the mere occurrence of such negative events would not suffice to exert large-scale influences on anti-immigrant attitudes. Indeed, the sociological literature tells us that any event will have little effect on public opinion unless it is turned into a major event by the mass media (Molotch and Lester, 1974; Lewis, 2000, p. 203f.). Nevertheless, more detailed explorations in this vein could constitute a profitable focus of research.

In sum, the current study represents a comprehensive investigation of how negative immigration-related news reports impact natives' perceived group threat, both 
independently and in interaction with immigrant group size. Therefore, the theoretical framework and empirical findings documented here may provide a fruitful research perspective whenever contextual sources of antiimmigrant sentiments are the focus of interest.

\section{Notes}

1. For similar conceptualizations, see e.g. Kellstedt (2000), Koopmans and Olzak (2004) or Lubbers and Scheepers (2001).

2. Detailed sources of information on the immigrant population in Spain at different levels of aggregation are available on the INE website, e.g. http://www .ine.es/jaxi/menu.

do?type $=$ pcaxis\&path $=\% 2 \mathrm{Ft} 20 / \mathrm{e} 245 \&$ file $=$ inebase

$\& \mathrm{~L}=1$ (accessed Oktober 17, 2010)

3. A more pragmatic reason to focus on this period is that LexisNexis, our central source for collecting data on negative immigration-related news reports, covers digital full texts of 'El Pais' only since 1996.

4. One may criticize that the first item assessing respondents' perceived size of the immigrant population taps a different dimension than the remaining items used to measure perceived group threat. This argument rests on the idea that, from a conceptual perspective, 'perceived size' and 'perceived group threat' represent two distinct concepts. However, in previous research it has been shown that numerical estimates of the size of the immigrant population are associated with various measures of perceived group threat (Semyonov, Raijman and Gorodzeisky, 2008; Schlueter and Scheepers, 2010). Moreover, we would like to note that rather than asking for subjective estimates of the immigrant population, the response options of the 'size' item used in this study clearly ask for an evaluation of the perceived size of the immigrant population. To explore the robustness of our findings, we reran all models with the threat-index constructed without the 'size' item. The results were essentially the same, so our choice has no substantial influence on the findings. Nevertheless, we consider the question how to assess subjective estimates of an outgroup's numerical size, perceived group threat and related constructs as important areas for future research.

5. Since no information on the regional percentage of non-Western immigrants was available for 1997, we substituted these data using the regional averages between 1996 and 1998.

6. One example of the syntax used for this search string reads as follows: (headline ('trabajaderos extranjeros' OR 'sin papeles' OR 'inmigrantes' OR 'inmigracion') AND ('trabajaderos extranjeros' OR 'sin papeles' OR 'inmigrantes' OR 'immigracion' w/p illegal! OR conflict! OR confront! OR policia! OR guardia! OR delincuenc! OR criminal! OR integrac! OR lengu! OR deportacion).

7. An added benefit of using a temporally lagged predictor is that it alleviates concerns regarding the direction of causality from negative immigration-related news reports to perceptions of group threat. We acknowledge, of course, that temporal separation is a necessary but not sufficient condition to establish causal conclusions. A closer look at the direction of causality remains a topic for future research.

8. Notice that related studies successfully identify relevant newspaper articles using a single key word only (e.g. Lubbers and Scheepers, 2001), or refrain from manual reanalyses of the sampled newspaper articles. In light of this, our operationalization represents a rather detailed approach to quantify the frequency of negative immigration-related newspaper reports over time.

9. We decided to avoid including political orientation as a control variable since it had more than 20 per cent missing values on average. However, imputing missing values and including this variable in the model did not have any effect on our conclusions.

10. We also estimated three-level hierarchical models using restricted maximum likelihood techniques (REML) as well as Bayesian Markov-Chain Monte-Carlo methodology (MCMC). The results from these alternative models confirmed all substantial conclusions reported here. Additionally, we also estimated a series of cross-classified multilevel models which partitioned the variance in our dependent variable perceived group threat along regions, time points plus a region $\times$ time point combination. Again, the results from these alternative model specifications confirmed all of our substantial findings.

11. Relaxing this constraint by allowing for randomly varying slopes did not alter our conclusions.

12. To account for the unequal variance in the measure of immigrant group size, we re-estimated all of our 
models using log-transformed regional percentage scores. Using the log-transformed values also accounts for the slight curvilinear trend concerning the association between the immigrant group size and perceived group threat. Apart from small changes in the size of the slope coefficients for the main effects and the percentage immigrant $\times$ negative mass media reports interaction, all these models confirmed our substantial conclusions from the models 1 to 4 . Accordingly, we decided not to present these somewhat more complicated models here. Instead, we focus on the more parsimonious models using untransformed variables and examine linear associations only. Additional analysis also revealed that alternative specifications of the immigrant group size measure (e.g. with- and without Latin American immigrants) lead to very similar results in Model 1 to 4 .

13. We also plotted the longitudinal trend in immigration-related negative news reports shown in Figure 2 against a simple count of articles containing the keyword 'immigr' ${ }^{\star}$ ' in their headlines from an alternative news source, namely, the Spanish national daily ' $\mathrm{ABC}$ '. While the results differed somewhat in terms of absolute frequencies, the longitudinal patterns were highly similar.

14. To determine whether the slopes of the higher-level predictor variables were affected by multicollinearity, we also estimated models where each of the predictors (except the interaction term) was entered one at a time. The results from these separate models confirmed all of our substantial conclusions based on models 1 to 4 . Furthermore, to make sure the findings are not affected by influential cases, we inspected the residuals of our models at the three levels of analysis. Models with selectively excluded cases did not alter our findings and, thus, lend further support to the robustness of the results presented here.

15. We also experimented with different transformations of the regional unemployment variable in order to check whether this would alter our findings. However, we never detected a significant effect of regional unemployment on perceived group threat.

16. Notice that in addition to contemporary levels of immigrant group size, some authors use the change in immigrant group size over specific periods to assess the influence of recent increases in interethnic competition on anti-immigrant attitudes. We computed a series of alternative models including the annual change in immigrant group size. The additive effects remained significantly positive, but the (negative) interaction term between the change of the immigrant group size and negative immigrant-related news coverage was not significant. For the sake of parsimony, we decided to keep with our original model specification focusing on contemporary levels of immigrant group size only.

17. We were concerned whether our operationalization and model tests neglect the potential impact of the Madrid train bombings from the 11th March 2004 as a hostile event shaping anti-immigrant attitudes (Echebarria-Echabe and Fernandéz-Guede, 2006). Yet as Figure 2 shows, Spanish citizens' perceptions of group threat attributed to immigrants apparently do not reveal any noticeable peaks in the time of the Madrid bombings. This finding is possibly due to the rather long time lag between the day the terrorist attacks in Madrid took place and the field phase of the survey (beginning in November 2004). Of course, different results could have been expected, if, for example, survey data, which are temporally closer to the terrorist event would have been at our disposal. In this respect, we would like to note that existing theory and research leads us to expect that it is rather the reports about the hostile events in the mass media than the events themselves which shape people's perceptions of group threat (Molotch and Lester, 1974; see also Kellstedt, 2000: 274).

\section{Acknowledgements}

We thank two anonymous reviewers for comments on an earlier version of the paper.

\section{Supplementary Data}

Supplementary data are available at ESR online.

\section{References}

Agrela, B. (2002). Spain as a Recent Country of Immigration: How Immigration Became a Symbolic, Political, and Cultural Problem in the 'New Spain'. Working Paper 57, The Center for Comparative Immigration Studies, University of California, San Diego.

Allport, G. W. (1954). The Nature of Prejudice. Reading, MA: Addison-Wesley. 
Arango, J. (2000). Becoming a country of immigration at the end of the twentieth century: the case of Spain. In: King, R., Lazaridis, G. and Tsardanidis, C. (Eds.), Eldorado or Fortress? Migration in Southern Europe. New York: St Marin's Press, pp. 253-276.

ASEP (Análisis Sociológicos Económicos y Políticos)/JDS (2008). The Two Faces of Immigration 1991-2007 [Dataset]. Madrid: ASEP/JDS.

Blalock, H. M. (1967). Toward a Theory of Minority Group Relations. New York: John Wiley \& Sons.

Blumer, H. (1958). Race prejudice as a sense of group position. Pacific Sociological Review, 1, 3-7.

Boomgaarden, H. G. and Vliegenthart, R. (2009). How news content influences anti immigration attitudes: Germany, 1993-2005. European Journal of Political Research, 48, 516-542.

Ceobanu, A. M. and Escandell, X. (2010). Comparative analyses of public attitudes toward immigrants and immigration using multinational survey data: a review of theories and research. Annual Review of Sociology, 36, 309-328.

CIPIE (Centro de Investigaciones, Promoción y Cooperación Internacional) (1999). Imigración y Racismo. Análisis de Radio, Televisión y Prensa Espanola. Available from <http://www.eurosur.org/ CIPIE/prensa.htm $>$ [accessed 3 April 2009].

Coenders, M. (2001). Nationalistic Attitudes and Ethnic Exclusionism in a Comparative Perspective: An Empirical Study of Attitudes toward the Country and Ethnic Immigrants in 22 Countries. Nijmegen: ICS Dissertation, ICS/Radboud University Nijmegen.

Corkill, D. (2001). Immigration, the Ley de Extranjería and the Labour Market in Spain. International Journal of Iberian Studies, 14, 148-157.

Curran, P. J., West, S. G. and Finch, J. (1996). The robustness of test statistics to non-normality and specification error in confirmatory factor analysis. Psychological Methods, 1, 16-29.

Dearing, J. W. and Rogers, E. M. (1996). Agenda-Setting. Thousand Oaks: Sage.

Echebarria-Echabe, A. and Fernández-Guede, E. (2006). Effects of terrorism on attitudes and ideological orientation. European Journal of Social Psychology, 36, 259-265.

Escandell, X. and Ceobanu, A. (2009). When contact with immigrants matters: threat, interethnic attitudes and foreigner exclusionism in Spain's comunidades autonomas. Ethnic and Racial Studies, 32, 44-69.

Hagendoorn, L. and Pepels, J. (2003). Why the Dutch maintain more social distance from some ethnic minorities than others: a model explaining the ethnic hierarchy. In: Hagendoorn, L., Veenman, J. and Veenman Vollebergh, W. (Eds.), Integrating
Immigrants in the Netherlands: Cultural versus Socio-Economic Integration. Aldershot: Ashgate, pp. 41-62.

Hjerm, M. (2009). Anti-immigrant attitudes and crossmunicipal variation in the proportion of immigrants. Acta Sociologica, 52, 47-62.

Hopkins, D. (2010). Politicized places: explaining where and when immigrants provoke local opposition. American Political Science Review, 104, 40-60.

Hox, J. (2002). Multilevel Analysis: Techniques and Applications. Mahway, NJ: Erlbaum.

INE (Instituto Nacional de Estadística) (2008). Available from $<$ http://www.ine.es/jaxi/menu.do?type $=$ pcaxis $\&$ path $=\% 2 \mathrm{Ft} 20 /$ e245\&file $=$ inebase $\& \mathrm{~L}=1>$ [accessed 3 April 2009].

Kellstedt, P. M. (2000). Media framing and the dynamics of racial policy preferences. American Journal of Political Science, 44, 245-260.

Koopmans, R. and Olzak, S. (2004). Discursive opportunities and the evolution of right-wing violence in Germany. American Journal of Sociology, 110, 198-230.

Kunovich, R. M. (2009). The sources and consequences of national identification. American Sociological Review, 74, 573-593.

LaHuis, D. M. and Ferguson, M. W. (2009). The accuracy of significance tests for slope variance components in multilevel random coefficient models. Organizational Research Methods, 12, 418-435.

LeVine, R. A. and Campbell, D. T. (1972). Ethnocentrism. Theories of Conflict, Ethnic Attitudes, and Group Behavior. New York: Wiley.

Lewis, C. W. (2000). The terror that failed: public opinion in the aftermath of bombing in Oklahoma City. Public Administration Review, 60, 201-210.

LexisNexis (2008). LexisNexis Wirtschaft. Available from $<$ http://www.lexisnexis.com.proxy.ub.uni-frankfurt. de/de/business/home/home.do?randomNum $=0$. 7012744232137756> [accessed 14 July 2008].

Lubbers, M. and Scheepers, P. (2001). Explaining the trend in extreme right-wing voting: Germany 1989-1998. European Sociological Review, 17, 431-449.

Luke, D. A. (2004). Multilevel Modeling. Thousand Oaks, CA: Sage.

Molotch, H. and Lester, M. (1974). News as purposive behavior: on the strategic use of routine events, accidents, and scandals. American Sociological Review, 39, 101-112.

Neuendorf, K. A. (2007). The Content Analysis Guidebook. Thousand Oaks: Sage.

Newton, K. (2006). May the weak force be with you: the power of the mass media in modern politics. European Journal of Political Research, 45, 209-234. 
Persson, A. V. and Musher-Eizenmann, D. R. (2005). College students' attitudes toward Blacks and Arabs following a terrorist attack as a function of varying levels of media exposure. Journal of Applied Social Psychology, 35, 1879-1893.

Peter, J. (2004). Our long 'return to the concept of powerful mass media': a cross-nationally comparative investigation of the influence of consonant media coverage on support for European integration. International Journal of Public Opinion Research, 16, 144-168.

Pettigrew, T. (1985). New Black-White patterns: how best to conceptualize them? Annual Review of Sociology, 11, 329-346.

Riek, B. M., Mania, E. W. and Gaertner, S. L. (2006). Intergroup threat and outgroup attitudes: a metaanalytic review. Personality and Social Psychology Review, 10, 336-353.

Schafraad, P., Wester, F. and Scheepers, P. (2006). Using 'new' data sources for 'old' newspaper research: developing guidelines for data collection. Communications, 31, 455-467.

Scheepers, P., Gijsberts, M. and Coenders, M. (2002). Ethnic exclusionism in European countries: public opposition to civil rights for legal migrants as a response to perceived ethnic threat. European Sociological Review, 18, 17-34.

Schlueter, E. and Scheepers, P. (2010). The relationship between outgroup size and anti-outgroup attitudes: a theoretical synthesis and empirical test of group threat and intergroup contact theory. Social Science Research, 39, 285-295.

Schlueter, E., Schmidt, P. and Wagner, U. (2008). Disentangling the causal relations of perceived group threat and outgroup derogation: cross-national evidence from German and Russian panel surveys. European Sociological Review, 24, 567-581.

Schlueter, E. and Wagner, U. (2008). Regional differences matter: examining the dual influence of the regional size of the immigrant population on derogation of immigrants in Europe. International Journal of Comparative Sociology, 49, 153-173.

Schmitt-Beck, R. (2003). Mass communication, personal communication and vote choice. the filter hypothesis of media influence in comparative perspective. British Journal of Political Science, 33, 233-259.

Semyonov, M., Raijman, R. and Gorodzeisky, A. (2006). The rise of anti-foreigner sentiment in European societies, 1988-2000. American Sociological Review, 71, 426-449.

Semyonov, M., Raijman, R. and Gorodzeisky, A. (2008). Foreigners' impact on european societies: public views and perceptions in a cross-national comparative perspective. International Journal of Comparative Sociology, 49, 5-29.

Shrum, L. J. (2009). Media consumption and perceptions of social reality: effects and underlying processes. In: Jennings, B. and Oliver, M. B. (Eds.), Media Effects: Advances in Theory and Research, 3rd edition. New York: Psychology Press, pp. 50-73.

Sniderman, P. M., Hagendoorn, L. and Prior, M. (2004). Predispositional factors and situational triggers: exclusionary reactions to immigrant minorities. American Political Science Review, 98, 35-50.

Snijders, T. A. B. and Bosker, R. J. (1999). Multilevel Analysis. An Introduction to Basic and Advanced Multilevel Modeling. London, Thousand Oaks and New Delhi: Sage.

Stephan, W. G. and Renfro, L. C. (2002). The role of threats in intergroup relations. In: Mackie, D. and Smith, E. R. (Eds.), From Prejudice to Intergroup Emotions. New York: Psychology Press, pp. 191-208.

Strabac, Z. and Listhaug, O. (2008). Anti-Muslim prejudice in Europe: a multilevel analysis of survey data from 30 countries. Social Science Research, 37, 268-286.

Tajfel, H. (1978). Differentiation between Social Groups. Studies in the Social Psychology of Intergroup Relations. London: Academic Press.

ter Wal, J. (2003). Racism and cultural diversity in European media: a review of research. Paper presented at the National Conference of the Federal Commission against Racism, «Parler non pas de, mais avec les minorités - Le racisme et les minorités dans les médias», Bern University, 21 March 2003.

ter Wal, J., d'Haenens, L. and Koeman, J. (2005). (Re) presentation of ethnicity in EU and Dutch domestic news. Media, Culture and Society, 27, 937-950.

Ullrich, J., Christ, O. and Schlüter, E. (2006). Merging on Mayday: subgroup and superordinate identification as joint moderators of threat effects in the context of European Union's expansion. European Journal of Social Psychology, 36, 857-876.

van Dijk, T. A. (2006). Racism and the Press in Spain. Barcelona: Universitat Pompeu Fabra. Available from $<\mathrm{http} / /$ www.discursos.org/unpublished\%20articles/ Racism\%20and\%20the\%20press\%20in\%20Spain. htm $>$ [accessed 3 April 2009].

Zaller, J. (1996). The myth of massive media impact revived: new support for a discredited idea. In: Mutz, D., Brody, R. and Sniderman, P. (Eds.), Political Persuasion and Attitude Change. Ann Arbor: University of Michigan Press, pp. 17-79.

Zucker, H. G. (1978). The variable nature of news media influence. In: Ruben, B. D. (Ed.), Communication Yearbook 2. New Brunswick: Transaction, pp. 225-240. 